\title{
Medicine by numbers
}

\author{
Theodora Bloom deputy editor
}

The BMJ

What's the evidence that any of the 150000 health apps available in Europe actually work? Not much, says Stephen Armstrong (doi:10.1136/bmj.h4597). Health professionals and lay people use them to monitor, manage, and even treat conditions. But apps are not heavily regulated. Compliance focuses on data protection and honest advertising, with few apps categorised as "medical devices" that need regulation by such organisations as the UK Medicines and Healthcare Products Regulatory Agency or the US Food and Drug Administration. The NHS Choices Health Apps Library lists apps found to be clinically safe and legally compliant. Meanwhile the Royal College of Physicians advises its members to use only apps that have a CE certificate. The UK government proposes a four stage assessment of apps, ranging from a crowdsourced initial stage to robust independent assessment, possibly involving the National Institute for Health and Care Excellence. But it's unclear whether this assessment will have legal force; and it might process at most 10000 apps a year.

Also without good evidence are calcium supplements or increased dietary calcium for reducing fracture risk in older people. Two research articles by Mark Bolland and colleagues published this week (doi:10.1136/bmj.h4580, doi:10.1136/bmj. h4183) make it plain that dozens of clinical trials with tens of thousands of participants have shown only a tiny effect on bone density in people who otherwise have a normal varied diet and no clinically relevant effect on fracture risk. Why then, asks Karl Michaëlsson in a linked editorial (doi:10.1136/bmj.h4825), do so many organisations continue to recommend intake of high levels of calcium and vitamin $\mathrm{D}$ that cannot be achieved by diet alone? The profitability of the global supplements industry might play a part, he speculates, noting how difficult it is to identify the influence of industry on people who write dietary recommendations.
Such interests are, of course, rife across healthcare. Timothy Anderson and colleagues (doi:10.1136/bmj.h4826) have quantified the links between academic leaders and US healthcare companies, including those producing medical equipment and biotechnology as well as drugs. In 446 publicly traded companies, they identified 279 directors affiliated with 85 non-profit academic institutions who collectively received nearly $\$ 55 \mathrm{~m}(£ 36 \mathrm{~m}$; $€ 50 \mathrm{~m})$ in individual payments (median individual compensation $\$ 193000$ ) alongside tens of thousands of company shares. Although some academic institutions place limits on the amounts their staff can receive from companies, David Rothman asks in a linked editorial (doi:10.1136/bmj.h5065), "Why is $\$ 5000$ a day acceptable but not $\$ 50000$ ?' He recommends just saying no: non-profit medical leaders should be excluded from directorships of healthcare companies.

It may seem obvious that explosives and chemical weapons used in conflicts such as the current one in Syria affect civilian men, women, and children as well as combatants. Not so clear are how large the effects and how disproportionately they affect different populations. Debarati Guha-Sapir and colleagues (doi:10.1136/bmj.h4736) use the registries of violent deaths produced by human rights groups and non-governmental organisations to reveal the numbers behind the devastating effects of aerial bombardment and ground level explosives that have killed tens of thousands of Syrian civilians. As Hamit Dardagan notes in his linked editorial (doi:10.1136/bmj.h5041), these data underline the urgent need to ban the use of indiscriminate weapons in populated areas. We must hope these numbers prove persuasive.

Cite this as: BMJ 2015;351:h5228

๑ BMJ Publishing Group Ltd 2015 